\title{
PREFACE TO SECOND EDITION
}

Were a survey undertaken of the faunal kingdom for deciding on the class exhibiting the greatest beauty of form and color, it would be natural to anticipate a fair range of choices among individual judges, based in no small degree upon each one's comparative interest, familiarity and personal involvement with animals belonging within certain taxonomic categories.

Human subjectivity, being what it is, must in the end confer added richness to the unavoidable comparisons which daily confront the naturalist, or groups of them.

Close or personal association with researches across a generous spectrum of animal types should, one might assume, contribute toward increased objectivity in a comparative survey. It is not as though one were confronted with the solemn and ultimately fateful judgment which the Greek shepherd Paris was called upon to render concerning the comparative pulchritude of the three goddesses Hera, Minerva and Aphrodite.

In the first instance the inquiry posed to a naturalist is academic, and his choice concerns nobody save himself. Moreover, a reasonable breadth of appreciation may confer upon such a judge the ability to apply several kinds of special qualifications leading to gratifying, plural decisions. Thus, even such possible candidates as the scorpion, octopus or baboon should enjoy their own finite chances for placement.

Retrospective reflection recalls to mind personal association, at various times across the years, with a considerable variety of animal forms. Pigmentary and other studies in the laboratory have been concerned with unicellular phytozoans, sponges, coelenterates (anemones, corals, jellyfish and siphonophores), various worms (flatworms, sipunculids, and annelids), echinoderms (sea-stars, sea-urchins and sea-cucumbers), bivalved, gastropod and cephalopod molluscs, arthropods (crustaceans and schemochromes of a few insects), cyclostomes, teleostean and elasmobranch fishes, reptiles and birds.

In an early paragraph of the Introduction to the first edition of this book, it was pointed out that, despite the great diversity in organismic form, based upon incalculable numbers of different, successive linkages between the amino acids constituting the proteins of species, there exist far fewer classes (hardly exceeding a dozen) of biochrome to fulfill the diversified coloration and patterning seen in the animal kingdom.

Hence the appreciation of the comparative biochemist, who must of necessity also be a naturalist, is led into expanding realms, each with its own charm.

In what I write below, I confess at the outset to having exercised somewhat arbitrary options in the presentation of examples in a supplementary section. Attempts at an all-inclusive revision would have stretched the task beyond the reasonable proportions chosen to fulfill the basic purposes set forth in the beginning. 
During the two decades since the first printing of this book by the Cambridge University Press, studies of animal biochromes have become steadily more enticing and more intense, while the significance of the subject has deepened in several disciplines of biology. As a consequence, reviews of specific areas have appeared within the wide boundaries of the field, complementing our understanding and appreciation of biological pigments in general.

But in the period since 1966, when the first edition of this book became exhausted in supply, there have been many expressions of hope from friends and fellow scientists that a succeeding edition or reprinting of the book might be expected. Several publishers have communicated similar gratifying wishes, accompanied by invitations.

The appearance or particular anticipation of new books or extended review treatments relating to animal biochromy have admittedly contributed to reasons for my delay in undertaking another immersion in the task. I had, moreover, published numerous research papers, and chapters or other reviews, within this general field of reference, which postponed further my taking up this assignment once again.

Since the primary purpose of the work is to present to students and other interested readers a survey of the fundamental physical and chemical features responsible for color manifestation in animals, but not to cover in toto recent advances relating to the identity and metabolism of all newly studied biochromic representatives, I readily agreed, with two provisos, to the reprinting of the first edition of Animal Biochromes, now by the University of California Press. The first condition was that the author be allowed to screen the whole current text with some care, attempting to delete errors and to modify certain passages scattered through its pages. The second reservation involved the inclusion of a supplemental section, to be inserted at the end of the book, attempting to bring up to date at least a few of the more recent findings relating to certain of the more conspicuous and important animal pigments, most notably among the carotenoids, tetrapyrroles and melanins. The Supplement includes its own alphabetically tabulated bibliography and its separate indices by subject and author. Hopefully these latter arrangements may combine to keep the book within reasonable access of all who may desire to own a copy, while not placing readers to excessive inconvenience through the inclusion of both an original and a newer additional set of references and indices.

It will be noticed that, in the Supplement to this Second Edition, some minor changes occur, for example, in alternative conventional spelling of certain words, and the newly adopted designation of $\mathrm{nm}$ (= nannometers) replacing the older equivalent $\mathrm{m} \mu$ (= millimicra) for reference to the $\lambda_{\max }$ (= maximal light-absorption locus) of a pigment in a reference solvent. Structural formulae are presented in greatly simplified, modern form.

Of any avid readers and uncited authors alike I would ask forgiveness if, in the compelling interest of spatial economy while seeking to indicate instances of more recent and important findings regarding animal biochromes, I may have emphasized references to written reviews, themselves citing many 
PREFACE TO SECOND EDITION

original sources, and to reports of investigations wherein I shared first-hand experience.

Again, I thank many friends and colleagues, including officers and staff members of the University of California Press, for the numerous kindnesses and assistance accorded me toward the completion of this Second Edition. 